\title{
Elementos de arquitetura da informação no Repositório Eletrônico Institucional da UFPB
}

\author{
Felipe Carvalho Marinho Gusmão \\ Graduando em Arquivologia na Universidade Federal da Paraíba (UFPB) \\ E-mail: fcmgusmao@gmail.com \\ Mayane Paulino de Brito e Silva \\ Mestranda em Ciência da Informação na Universidade Federal da Paraíba (PPGCI/UFPB) \\ E-mail: mayanepaulino.b@gmail.com \\ Giuliane Monteiro Pereira \\ Bibliotecária na Biblioteca Central da Universidade Estadual da Paraíba, \\ Mestra em Ciência da Informação pela Universidade Federal da Paraíba (PPGCI/UFPB) \\ E-mail: giulianne.monteiro@gmail.com \\ Izabel França de Lima \\ Professora Adjunta do Departamento de Ciência da Informação e do Programa de Pós-Graduação em \\ Ciência da Informação da Universidade Federal da Paraíba. \\ Professora do Programa de Pós-Graduação em Gestão nas organizações aprendentes do Centro de \\ Educação. \\ E-mail: belbib@gmail.com \\ Henry Poncio Cruz de Oliveira \\ Professor Adjunto do Departamento de Ciência da Informação da Universidade Federal da Paraíba \\ (UFPB) \\ E-mail: henry.poncio@gmail.com
}

\begin{abstract}
RESUMO:
Os ambientes de informação podem ser analógicos, digitais ou híbridos. Neste trabalho damos atenção aos ambientes de informação digital, que englobam os sítios da web, as bibliotecas digitais, os periódicos eletrônicos, os sistemas de gestão eletrônica de documentos e os repositórios digitais. O presente artigo é o relato de uma investigação sobre Arquitetura da informação em repositórios digitais, com foco analítico no repositório institucional da UFPB. Objetivou-se analisar elementos da Arquitetura da Informação nos Sistemas de organização com ênfase no modelo top down, do Sistema de rotulagem, navegação e busca na interface do repositório institucional da UFPB. A metodologia adotada é de caráter quali-quantitativo, com fins exploratórios e descritivos. Sugere-se melhorias na interface do Repositório Eletrônico Institucional da UFPB seguindo parâmetros orientados pela Arquitetura da informação com o intuito de aprimorar principalmente os processos de organização, busca e navegação.
\end{abstract}

Palavras-chave: Informação e tecnologia. Arquitetura da informação. Repositórios digitais. Repositório institucional - UFPB.

\begin{abstract}
:
Information environments can be analog, digital or hybrid, in this work we give attention to digital information environments, which include web sites, digital libraries, electronic journals, the electronic management system documents and digital repositories. This article is the result of an investigation on the Information architecture in digital repositories, with an analytical focus on the institutional repository of UFPB. This study aimed to analyze elements of Information Architecture in organizational systems with emphasis on top-down model, labeling system,
\end{abstract}


navigation and search in the institutional repository of UFPB interface. The methodology adopted is qualitative and quantitative, with exploratory and descriptive purposes. It is suggested improvements in UFPB of Institutional Electronic Repository interface following parameters guided by the architecture of information in order to mainly improve organizational processes, search and navigation.

Keywords: Information and technology. Information architecture. Digital repositories. Institutional repository - UFPB.

\section{INTRODUÇÃO}

As Tecnologias de Informação e Comunicação (TIC) têm impactado nos diversos setores da sociedade propiciando mudanças efetivas nas práticas sociais, econômicas, políticas, tecnológicas e científicas. Trata-se da instalação de um paradigma de cunho sócio-tecnológico onde a informação se tornou condição sine qua non para o desenvolvimento dos sujeitos e das instituições.

No paradigma sócio-tecnológico contemporâneo, os sujeitos produzem informações e as disponibilizam nos mais diversos ambientes de informação digital que promovem "a interação entre os sujeitos, dos sujeitos com organizações e entre organizações" (OLIVEIRA, 2014, p. 18).

Os ambientes de informação podem ser analógicos, digitais ou híbridos. Neste trabalho damos atenção especial aos ambientes de informação digital, compreendendo-os como uma categoria com ampla tipologia que engloba os sítios da web, as bibliotecas digitais, os periódicos eletrônicos, os museus digitais, os sistemas de gestão eletrônica de documentos, os repositórios institucionais, entre outros (OLIVEIRA, 2014). Na ótica de autores como Camargo e Vidotti (2011), Oliveira e Vidotti (2012), Santos e Vidotti (2009), os ambientes de informação digital fazem referência aos diversos lugares de armazenamento e provisão de acesso às informações de natureza digital.

No interior da tipologia dos ambientes de informação digital estão os repositórios digitais, que por sua vez podem ser divididos em temáticos e institucionais. Segundo Viana e Arellano (2006) Os repositórios digitais são artefatos que proveem armazenamento de objetos digitais mantendo a capacidade de gerenciar material por longos períodos de tempo e prover o acesso apropriado. Os repositórios digitais objeto de investigação neste relato de pesquisa (VIANA; 
ARELLANO, 2006).

Porém, percebe-se no plano empírico que existem problemas recorrentes no acesso e uso de ambientes de informação digital, o que inclui os repositórios digitais. Neste ínterim, Concklin (1987) destaca os problemas como a desorientação (disorientation) e o transbordamento cognitivo (cognitive overhead) como recorrentes nos diversos tipos de ambientes de informação digital. Oliveira e Vidotti (2013) sugerem os problemas supracitados, e problemas de ordem navegacional, de organização e de recuperação da informação podem estar associados à questões qualitativas na Arquitetura da Informação desses ambientes.

Este relato se conecta a uma teia interinstitucional de pesquisa em informação e tecnologia que recebe fomento do CNPq, neste texto damos atenção especial à investigação no Repositório Institucional da Universidade Federal da Paraíba. Nosso objetivo é relatar uma pesquisa que analisou os elementos da Arquitetura da Informação na interface do Repositório Eletrônico Institucional (REI) da Universidade Federal da Paraíba (UFPB).

A análise aqui apresentada, tem o potencial de sugerir melhoramentos no que relacionados à estrutura arquitetural do Repositório Institucional da Universidade Federal da Paraíba e de outros repositórios institucionais. Este trabalho contribui na prática de pesquisas realizadas, no âmbito da Ciência da Informação, sobre Arquitetura da Informação em ambientes de informação digital, neste caso com foco nos repositórios institucionais.

\section{FUNDAMENTOS TEÓRICOS}

A pesquisa que aqui relatamos ocorreu no âmbito das Ciências Sociais Aplicadas e teve a Ciência da Informação como background interdisciplinar e teórico para produzir um conhecimento sobre a Arquitetura da Informação em Repositórios Institucionais. Doravante, abordaremos a Arquitetura da Informação e os Repositórios Institucionais do ponto de vista teórico.

\subsection{ARQUITETURA DA INFORMAÇÃO DIGITAL}


Neste trabalho, trataremos da perspectiva clássica da Arquitetura da Informação que se volta para às ações de navegação, organização, representação, busca e rotulagem da informação digital. A informação de natureza digital pode ser compreendida como tipo de informação gerada, gerida, manipulada, armazenada e distribuída pelas TIC (ILHARCO, 2003). Expandindo a noção apresentada por Ilharco (2003), Oliveira e Vidotti (2012, p. 275) acrescentam que toda informação digital é representada por meio da "[...] linguagem binária e armazenada em suportes digitais, independente das características de volatilidade do suporte, cujo acesso e uso se dão através de equipamentos computacionais (hardware e software) [...]".

O tipo de informação que tratamos neste trabalho, tem sido armazenada, organizada, representada, acessada, usada e reusada em ambientes de informação digital, que por sua vez, possuem uma arquitetura capaz de otimizar ou dificultar a experiência informacional dos sujeitos nestes ambientes.

Oliveira (2014) e Oliveira, Vidotti e Bentes Pinto (2015) asseveram que a Arquitetura da Informação tem sido empregada para o melhoramento do acesso e do uso da informação em ambientes analógicos e/ou digitais desde a década de 1980.

Macedo (2005, p. 143) enquadra a Arquitetura da Informação no âmbito científico e assevera que a ela tem características

[...] de uma disciplina que se estabelece no contexto da ciência pósmoderna. A ciência moderna pressupunha a necessidade de existência de uniformidades básicas e regularidades empíricas acerca do fenômeno que engloba o objeto de estudo de uma área, bem como a utilização de um método científico rigoroso para investigá-lo. Na pós-modernidade [...] esses pressupostos têm sido repensados. Os valores de universalidade e certeza têm dado lugar a pluralidade e a complexidade. E é nessa conjuntura que a área de Arquitetura da Informação se estabelece. Portanto, sua natureza é inerentemente interdisciplinar, e seus métodos, modelos e teorias são derivados de outras disciplinas.

Para Rosenfeld, Morville e Arango (2015) a Arquitetura da Informação pode ser descrita como: a) um desenho estrutural de ambientes de informação compartilhados; b) a síntese de sistemas de organização, rotulagem, busca e navegação dentro de ecologias digitais, físicas e cross-channel, c) a arte e a ciência de dar forma à produtos informacionais e experiências com suporte à usabilidade, encontrabilidade e compreensão. 
Para Oliveira (2014) o dinamismo da pós-modernidade gerou, por meio da interdisciplinaridade, quatro abordagens distintas na Arquitetura da Informação, conforme visto na figura 01.

A abordagem arquitetural é a primeira vertente que influencia a Arquitetura da Informação, sobretudo no contexto de seu nascimento e expansão. Tal abordagem gera uma Arquitetura da Informação com influência interdisciplinar da Arquitetura e do Design (OLIVEIRA, 2014).

A racionalidade sistêmica gerou, na Arquitetura da Informação, uma abordagem denominada sistêmica e fundamentada na Teoria Geral dos Sistemas do biólogo alemão Ludwig von Bertalanffy (1975) e nas possibilidades de aplicação da Al nos Sistemas de Informação (OLIVEIRA; VIDOTTI, 2012; OLIVEIRA, 2014).

Figura 1 - Abordagens da Arquitetura da Informação.

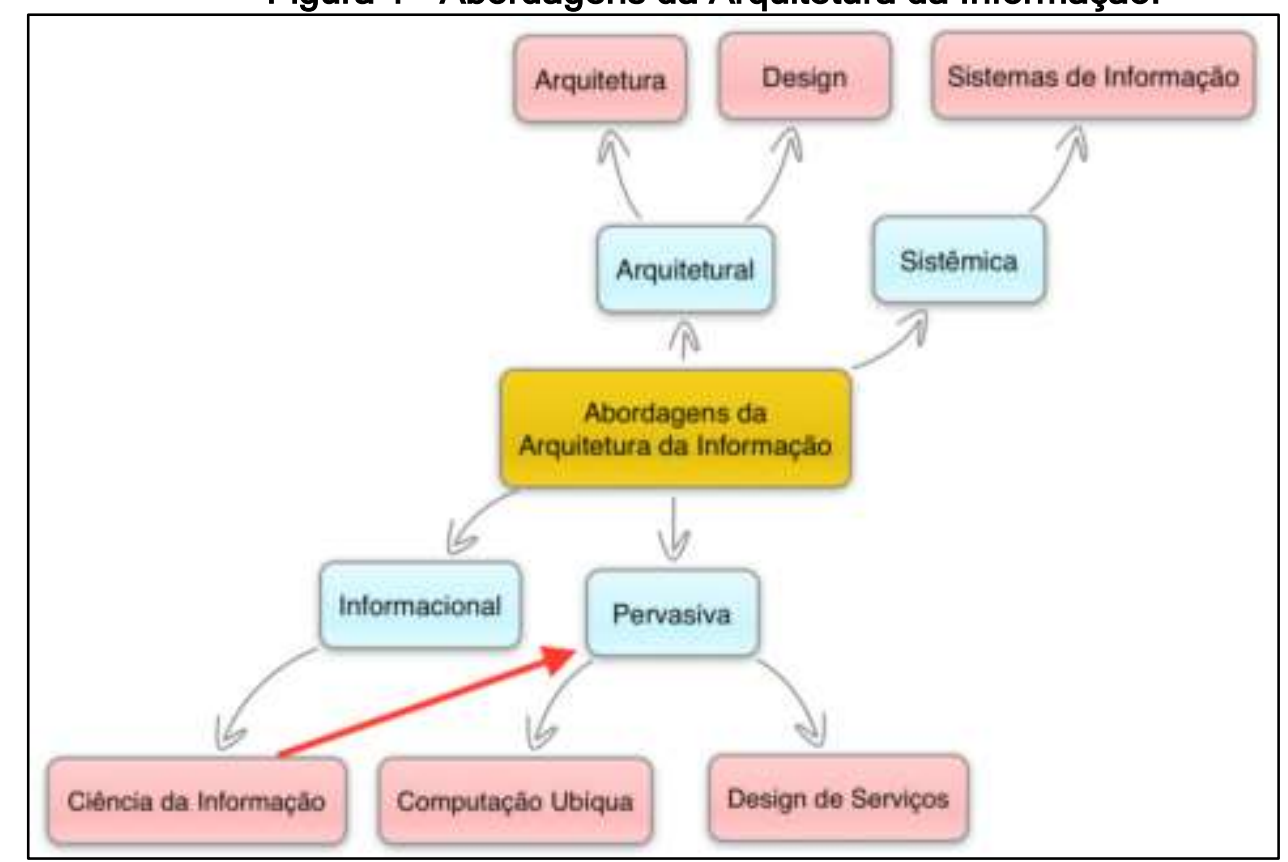

Fonte: Extraído de Oliveira (2014)

A abordagem informacional tem orientado os estudos e práticas da Arquitetura da Informação, de forma interdisciplinar esta abordagem estreitou relações teóricas o campo da Biblioteconomia e da Ciência da Informação (OLIVEIRA, 2014).

A vertente pervasiva da Arquitetura da Informação tem recebido contribuições de Resmini e Rosati (2011) e Oliveira (2014). Os autores supracitados compreendem a referida abordagem como sendo a mais nova e aquela que tem o 
potencial de responder as demandas informacionais e tecnológicas marcada pelo hibridismo de ambientes, pelas experiências cross-channel, pelas soluções ubíquas e pela pervasividade.

Para Oliveira (2014) as abordagens arquitetural, sistêmica e informacional são aplicáveis aos ambientes analógicos, digitais ou híbridos de informação e o que diferencia, radicalmente, a abordagem pervasiva das demais e sua aplicação nas ecologias informacionais complexas. Para este autor o objeto/fenômeno de investigação da Arquitetura da Informação Pervasiva são as ecologias Informacionais complexas.

Este estudo, transitou entre as abordagens sistêmica e interdisciplinar na medida que adotou, como referência conceitual, a compreensão de que a Arquitetura da Informação é um campo do conhecimento que

\begin{abstract}
enfoca a organização de conteúdos informacionais e as formas de armazenamento e preservação (sistemas de organização), representação, descrição e classificação (sistema de rotulagem, metadados, tesauro e vocabulário controlado), recuperação (sistema de busca), objetivando a criação de um sistema de interação (sistema de navegação) no qual o usuário deve interagir facilmente (usabilidade) com autonomia no acesso e uso do conteúdo (acessibilidade) no ambiente hipermídia informacional digital. (VIDOTTI; CUSIN; CORRADI, 2008, p.182).
\end{abstract}

O conceito apresentado acima, que recebe influências da Teoria Geral dos Sistemas mas também recebe a influência da Biblioteconomia e Ciência da informação, sendo oportuno para ser aplicado no contexto dos repositórios institucionais.

\title{
2.2 REPOSITÓRIOS DIGITAIS
}

Os repositórios digitais podem ser divididos entre temáticos e institucionais. Os repositórios temáticos cobrem uma determinada área temática do conhecimento. Por sua vez, os repositórios institucionais (RI) são sistemas de informação que armazenam, preservam, divulgam e dão acesso ao volume da produção intelectual e técnica de instituições e comunidades cientificas. Efetivam o armazenamento e lincagem de objetos informacionais em formato digital para serem ser acessados por diversos provedores de serviços nacionais e internacionais (VIANA; MARDERO ARELLANO, 2006). 
Ampliando a concepção dos repositórios institucionais, recorremos ao pensamento de Lynch (2003) que compreende um repositório institucional acadêmico como sendo um conjunto de serviços, que uma universidade oferece para os membros da sua comunidade e para sociedade em geral, com foco no gerenciamento e disseminação do material digital criado pelos sujeitos da instituição. Lynch (2003) ainda destaca o compromisso que uma instituição acadêmica dever efetivar para cuidar do material digital, incluindo a preservação a longo prazo, a organização, acesso e distribuição.

Alguns dos softwares livres mais usados no contexto dos Repositórios Institucionais são o E-prints, o Greeenstone, o Nou-Rau, o Fedora e o DSpace. Este último largamente utilizado por Instituições públicas brasileiras. Sayão e Marcondes (2009) apontam algumas de suas características:

O software E-prints possui a maior e mais distribuída base instalada, sendo o pioneiro do movimento de acesso livre. O software Greenstone possibilita a criação e disseminação de coleções digitais (SAYÃO; MARCONDES, 2009).

O Nou-Rau é um sistema de código aberto que implementa um sistema online para arquivamento, indexação, acesso controlado e mecanismos eficientes para busca de documentos digitais. O Nou-Rau recebe documentos digitais em diversos formatos, em seguida converte-os para texto puro (SAYÃO; MARCONDES, 2009).

O Fedora tem uma arquitetura e infraestrutura ampla para o armazenamento, gestão e disseminação de objetos digitais complexos, incluindo o relacionamento entre eles. O conceito central do sistema é um poderoso modelo de objeto digital que estabelece como unidade de informação o "objeto digital Fedora". O modelo apoia visões múltiplas de cada objeto e dos seus relacionamentos tornando o sistema uma ferramenta bastante flexível (SAYÃO; MARCONDES, 2009).

O DSpace captura, armazena, indexa, preserva e redistribui documentos em formato digital. Seu download e instalação são gratuitos e existe versão em língua portuguesa do programa. O Dspace é focado em preservação digital a longo prazo (SAYÃO; MARCONDES, 2009).

No contexto dos Repostórios Institucionais, vale destacar a proposta de acesso livre (open access) e também a proposta de arquivos abertos (open archives), na disseminação do conhecimento científico e do patrimônio cultural, representados pelos Open Archives Inatiative - OIA - e da Budapest Open Access Initiative - BOIA (LIMA, 2009). 


\title{
3 ASPECTOS METODOLÓGICOS
}

Conforme sinalizamos, este relato se conecta a uma teia interinstitucional de pesquisas em Ciência da Informação, tratando sobre informação e tecnologia, com fomento do CNPq. Este texto objetivou apresentar investigação dos elementos da Arquitetura da Informação na interface do Repositório Eletrônico Institucional da Universidade Federal da Paraíba.

No intuito de alcançar o objetivo proposto, delineamos a pesquisa que ora relatamos como sendo um estudo de Arquitetura da Informação, com alvos de natureza exploratória e descritiva. O referencial metodológico de investigação exploratória foi adotado, pois se procura ampliar o conhecimento acumulado e sistematizado sobre a temática científica da Arquitetura da Informação em interfaces de Repositórios Institucionais. A faceta descritiva permite expor as características dos elementos arquiteturais da interface do Repositório Eletrônico Institucional da UFPB, realizando possíveis correlações entre os atributos arquiteturais top-down (MORESI, 2003; ROSENFELD; MORVILLE; ARANGO, 2015).

Quanto à análise dos dados, pode ser classificada como qualitativa pois considera que

\begin{abstract}
há uma relação dinâmica entre o mundo real e o sujeito, isto é, um vinculo indissociável entre o mundo objetivo e a subjetividade do sujeito que não pode ser traduzido em números. A interpretação dos fenômenos e a atribuição de significados são básicas no processo de pesquisa qualitativa. O ambiente natural (de informação digital) é a fonte direta para coleta de dados e o pesquisador é o instrumento-chave. [...] Os pesquisadores tendem a analisar seus dados indutivamente. $O$ processo e seu significado são os focos principais de abordagem (MORESI, 2003, p. 8).
\end{abstract}

A coleta de dados foi realizada na primeira semana de agosto de 2016 com o auxílio de um computador/notebook com acesso à internet, um diário de campo para o registro dos comportamentos do Repositório, onde foram coletadas imagens da interface do Repositório utilizando a função print screen do teclado do computador.

Após a coleta de dados, realizamos a análise relacionando a interface do Repositório Eletrônico Institucional com a lista de itens da Arquitetura da Informação Top-Down, como ainda analisamos os Sistemas de organização, navegação, rotulagem e busca na perspectiva de Rosenfeld, Morville e Arango (2015). 


\section{RELATANDO A ARQUITETURA DA INFORMAÇÃO NA INTERFACE DO REPOSITÓRIO ELETRÔNICO INSTICIONAL DA UFPB}

O Repositório Eletrônico Institucional da UFPB tem o intuito de disseminar as produções acadêmicas de discentes e docentes da instituição supracitada.

Para a análise dos dados utilizamos como base teórico-metodológica os Sistemas descritos por Rosenfeld, Morville e Arango (2015), a saber: Sistema de organização, dando ênfase ao modelo de organização Top-down; Sistema de navegação, rotulagem e busca através da observação, identificando e relacionando os pontos em questão.

$\mathrm{Na}$ análise dos Sistemas de organização, navegação e rotulagem adotou-se uma abordagem qualitativa e o Sistema de busca fora analisada numa perspectiva predominantemente quantitativa.

\subsection{SISTEMA DE ORGANIZAÇÃO}

Organizar coisas com a finalidade de (re)localizar ou de poder indicar uma localização precisa para seu uso, faz parte do cotidiano do Ser humano desde a separação de animais no pasto, como ainda, a separação dos tipos de plantio na agricultura desde os tempos mais remotos, ou seja, desde que se há notícia da história da humanidade. Dessa forma, podemos afirmar que organizar para recuperar é algo intrínseco da natureza humana.

Rosenfeld, Morville e Arango (2015) explanam que a nossa compreensão do mundo é em grande parte determinada por nossa capacidade de organizar as informações.

No Sistema de organização, procurou-se analisar o modo em que as informações do Repositório Eletrônico Institucional da UFPB estão organizadas, estruturadas, etc.

A respeito do modelo de organização da Arquitetura da informação Top-down, também conhecido como organização de cima para baixo, são sistemas de organização de informações que possuem o foco no conteúdo básico que o usuário irá buscar, tendo a ideia de uma classificação hierárquica de forma que a informação possa ser recuperada facilmente (ROSENFELD; MORVILLE; ARANGO, 2015). 
O modelo top-down proporciona uma estrutura de alto nível para navegação, tendo o objetivo de organizar a pesquisa em categorias que fazem sentido para o usuário, ou seja, dividir a informação em uma estrutura hierárquica de uma maneira que o usuário possa recuperar a informação de seu interesse. (ROSENFELD; MORVILLE; ARANGO, 2015).

Primeiramente, buscou-se responder as questões top-down que de acordo com Rosenfeld, Morville e Arango (2015) são as mais comuns que os usuários têm ao chegar no local (página inicial de sites/repositórios), são elas:

\section{1- Onde estou?}

2- Eu sei o que estou procurando; como faço para pesquisar por isto?

3- Como faço para contornar este site?

4- O que é único e importante sobre esta organização?

5- O que está disponível neste site?

6- O que está acontecendo lá?

7- Como faço para interagir com eles através de outros meios/canais digitais populares?

8- Como faço para entrar em contato com um Ser Humano?

9- Qual é o seu endereço?

10-Como posso acessar minha conta?

Com base na figura 2, podemos destacar que o sistema de organização do REI/UFPB utiliza um menu verticalizado com as regiões de exibição dos conteúdos destacados pelo link na cor azulada.

Possui uma barra de rolagem, mas o usuário não necessita utilizá-la uma vez que não corta nenhuma informação contida na página inicial do Repositório. Através deste sistema, o usuário do REI pode encontrar todas as subpáginas do Repositório. Observou-se ainda que as decisões sobre a infraestrutura do Sistema de organização do REI são de natureza institucional.

Ao analisar a interface da página inicial do REI/UFPB foi possível identificar as respostas da maioria dos itens, com exceção das questões 7 e 9. Contudo, mesmo identificando as respostas da maioria dos itens, faz-se necessário fazer algumas observações.

Sobre a primeira questão “Onde estou?’, observou-se não há na página inicial do Repositório um elemento (seja ele imagético ou não) que apresente de forma 
explícita onde o usuário está, a não ser por uma breve apresentação sobre o Repositório. Ao entrar na página inicial o usuário se depara com uma logo que não demonstra a princípio nenhuma ligação com o Repositório e mesmo existindo um elemento textual que responda à questão ora apresentada, pode ainda assim, gerar dúvidas no usuário, se ele está na página do Repositório ou se está na página do Dspace (software/plataforma utilizada para a criação/desenvolvimento do REI). Acredita-se que uma customização mais personalizada para o Repositório poderia melhorar substancialmente na resposta à pergunta "Onde estou?". Cogita-se ainda que esse ponto da customização personalizada pode auxiliar em outras questões, a exemplo da segunda questão.

$\mathrm{Na}$ segunda questão "Eu sei o que estou procurando; como faço para pesquisar por isto?", o usuário pode encontrar facilmente duas caixas de pesquisa, porém, a fim de padronizar e auxiliar a busca, sugere-se substituir o nome "Busca Dspace" por "Busca no REl/Repositório", como ainda padronizar a língua utilizada no Repositório, deixando ainda a opção do usuário acessar em outras línguas.

Para responder a terceira questão "Como faço para contornar este site?" o usuário encontra na página inicial do REI/UFPB, duas opções: um menu "Navegar" que mostra um mapa com as opções de navegação do Repositório e ainda é possível encontrar um tutorial de como navegar e pesquisar no link "Ajuda” do REI.

Todavia, as orientações contidas no link "Ajuda” não se encontram na língua vernácula do país, no caso o português $B R$, podendo apresentar-se como uma barreira linguística para o usuário que não domina outros idiomas não-oficiais no país.

Sobre a quarta questão “O que é único e importante sobre esta organização?”, o usuário/pesquisador encontra poucas informações a respeito do Repositório, podendo se apresentar como uma dificuldade em um possível estudo. Tornando-se necessário entrar em contato com os administradores do REI a fim de obter mais informações básicas do Repositório, informações tais como: "Quando se criou o Repositório? A partir de que ano são as publicações do Repositório? etc.", informações básicas que já poderiam estar disponíveis na apresentação.

Para responder a quinta questão “O que está disponível neste site?”, o usuário encontra na página inicial do REI as comunidades pelas quais pode navegar. Porém, para acessar as coleções, é necessário que o usuário escolha uma comunidade por vez. Em versões mais atualizadas do Dspace é possível configurar essas comunidades com menus expansíveis, fazendo com que não seja obrigatória a 
entrada em uma comunidade por vez para o usuário encontrar o que deseja.

A respeito da sexta questão "O que está acontecendo lá?", o usuário encontra uma caixa de notícias, porém observou-se que os administradores do Repositório não alimentam com frequência essas informações. Essa ferramenta poderia ser utilizada com o intuito de divulgar a quantidade de acessos do Repositório ou ainda as últimas submissões realizadas no REI e outras informações que fossem úteis aos usuários do Repositório.

A sétima pergunta "Como faço para interagir com eles através de outros meios/canais digitais populares?", não pode ser respondida pois não há nenhuma indicação de outros meios/canais digitais que estejam disponíveis aos usuários no REI. Um exemplo de outro canal que poderia ser disponibilizado aos usuários é um aplicativo mobile onde os usuários poderiam ter um acesso mais rápido ao REI através dos smatphones/tablets, principalmente se levarmos em consideração de um dos princípios dos repositórios digitais que é oferecer amplo acesso à informação contida naquele repositório.

Sobre a oitava questão "Como faço para entrar em contato com um Ser Humano?", o usuário encontra ao final da página inicial do REI, um link "Feedback", onde se torna possível o contato do usuário com os administradores do Repositório. Contudo, a localização e indicação desse link poderia ser mais visível e fácil localização para os usuários com o intuito de facilitar de fato essa comunicação/interação. Sugere-se ainda a modificação do termo Feedback para "Contate-nos" ou simplesmente "Contato".

A nona questão "Qual é o seu endereço?" assim como a questão 7, também não é respondida ao usuário pois não há nenhuma indicação de endereço físico de onde o REI é administrado, o máximo que o usuário pode identificar é a instituição ao qual o Repositório pertence. Sugere-se que seja colocado na Página inicial a informação do endereço físico do local/setor responsável pela administração do REI para que não seja necessário o usuário entrar em contato com os administradores para obtê-la. Sugere-se ainda uma customização mais personalizada, com cores, logotipo da Instituição que administra, etc.

Quanto a última questão "Como posso acessar minha conta?”, o usuário encontra no REI o menu "Entrar". Esse menu contém três links distintos que redirecionam o usuário para a página de login.

Identificamos que há na interface do REI, regiões e funções que poderiam ser 
melhor utilizadas através de uma reestruturação do sistema de organização. Uma sugestão que acreditamos que possa melhorar o REl, principalmente nos aspectos que as questões acima pontuam, é atualizar o Repositório para uma versão mais recente, que permita uma configuração e customização mais personalizada.

Que o REI seja atualizado constantemente com mais informações a respeito do Repositório, das submissões e de sua própria história de criação e desenvolvimento.

E que em um futuro não tão distante, possam ser pensadas formas de ampliar o acesso e disseminação das informações contidas no REI, levando-se em consideração a rápida transformação/atualização das TIC, suportes e formatos disponíveis.

A Figura 2 retrata a imagem da interface da página principal do Repositório Eletrônico

Institucional da UFPB disponível em: http://rei.biblioteca.ufpb.br/jspui/, onde relacionamos as perguntas dos itens da Arquitetura top-down às respostas quando encontradas na interface da página principal do Repositório.

Figura 2 - Respostas às perguntas dos usuários na Interface da página inicial do REI/UFPB

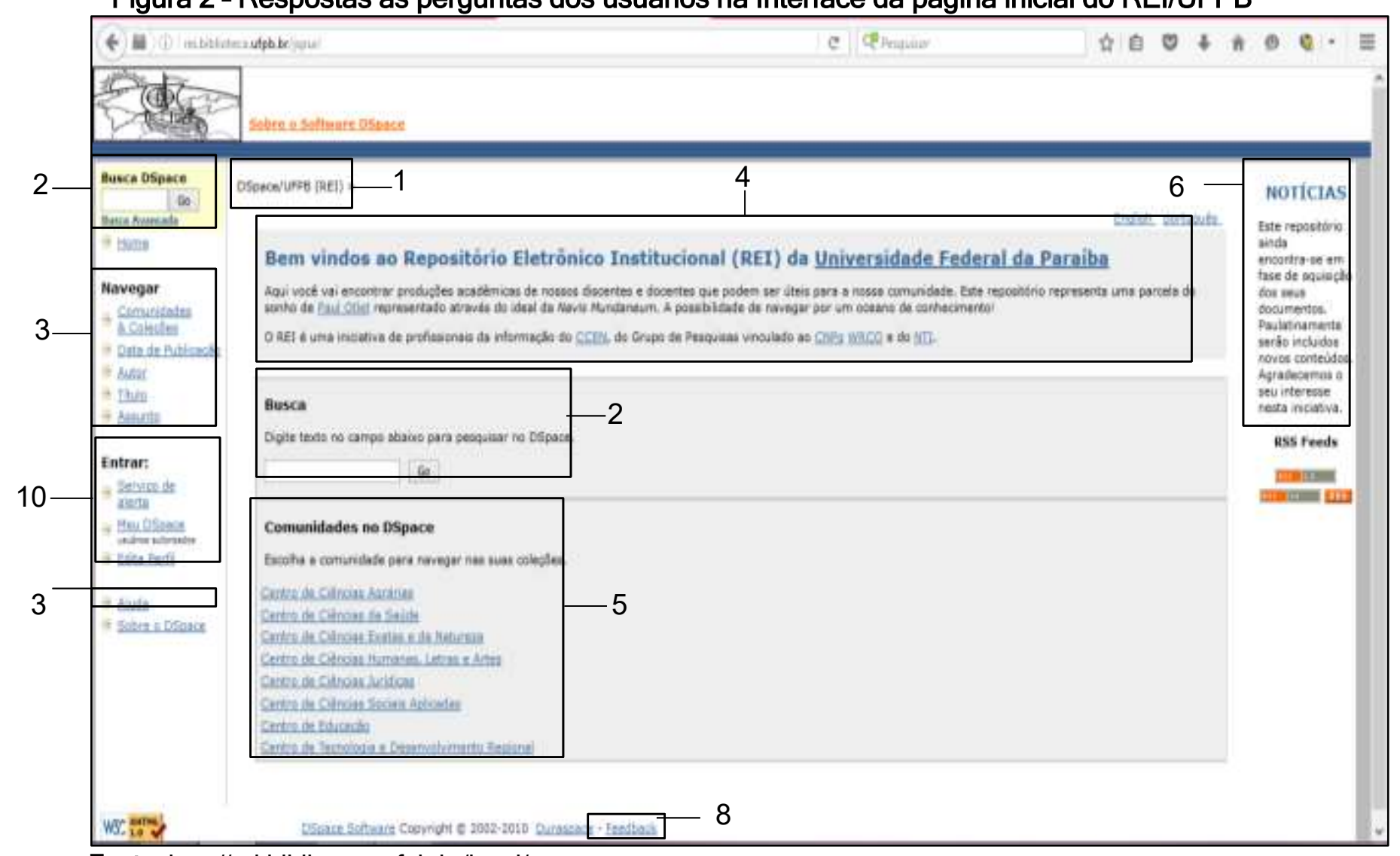

Fonte: http://rei.biblioteca.ufpb.br/jspui/ 
Nos tópicos a seguir discutiremos a análise do Repositório Eletrônico Institucional da UFPB na perspectiva dos Sistemas de navegação, rotulagem e busca na perspectiva de Rosenfeld, Morville e Arango (2015).

\subsection{SISTEMA DE ROTULAGEM}

Rotular nada mais é do que uma forma de representação, da mesma forma que usamos as palavras para representar pensamentos, os rótulos são nomenclaturas dadas aos itens dos menus, botões e textos que precisam ser clicados pelos os usuários para obter alguma instrução, esses rótulos podem ser identificados na forma textual ou não-textual (imagética), podendo ser de alto ou baixo nível. (ROSENFELD; MORVILLE; ARANGO, 2015)

Os rótulos textuais são aqueles representados por uma ou mais palavras, já o não-textual são representados por ícones/imagens pequenas que representam algum conceito e direciona ao detalhamento de algum tipo de informação. Sobre os níveis, os rótulos de baixo nível são utilizados de forma individual para navegação contextual e local. Já os de alto nível, são utilizados na navegação global nas categorias de assuntos e características de um site/portal. (ROSENFELD; MORVILLE; ARANGO, 2015)

Rosefeld, Morville e Arango (2015) explicam que o objetivo dos rótulos é comunicar a informação sem ocupar tanto espaço físico da página.

Com base no que fora exposto, analisamos o sistema de rotulagem da interface do REI, no quadro 1 apresentamos as regiões da interface do REI, cujos os rótulos foram analisados.

Quadro 1 - Análise do sistema de rótulos em regiões digitais do Repositório Eletrônico Institucional da UFPB

ROTULOS

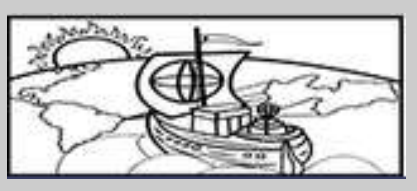

\section{ANALISE}

A região digital apresentada pode ser encontrada na página inicial do REI. Trata-se de um rótulo imagético que ao ser clicado redireciona o usuário para página inicial/home se o usuário estiver outra subpágina. Entende-se que ela possa ser o logotipo do Repositório Eletrônico Institucional da UFPB. Pode-se entender que a imagem remete ao ato de "navegar", tratando-se de um repositório científico, poderia significar "navegando sob as águas do conhecimento". Ressalta-se que esse é o entendimento dos autores, pois não há nenhuma informação a respeito dessa imagem no REI/UFPB. 


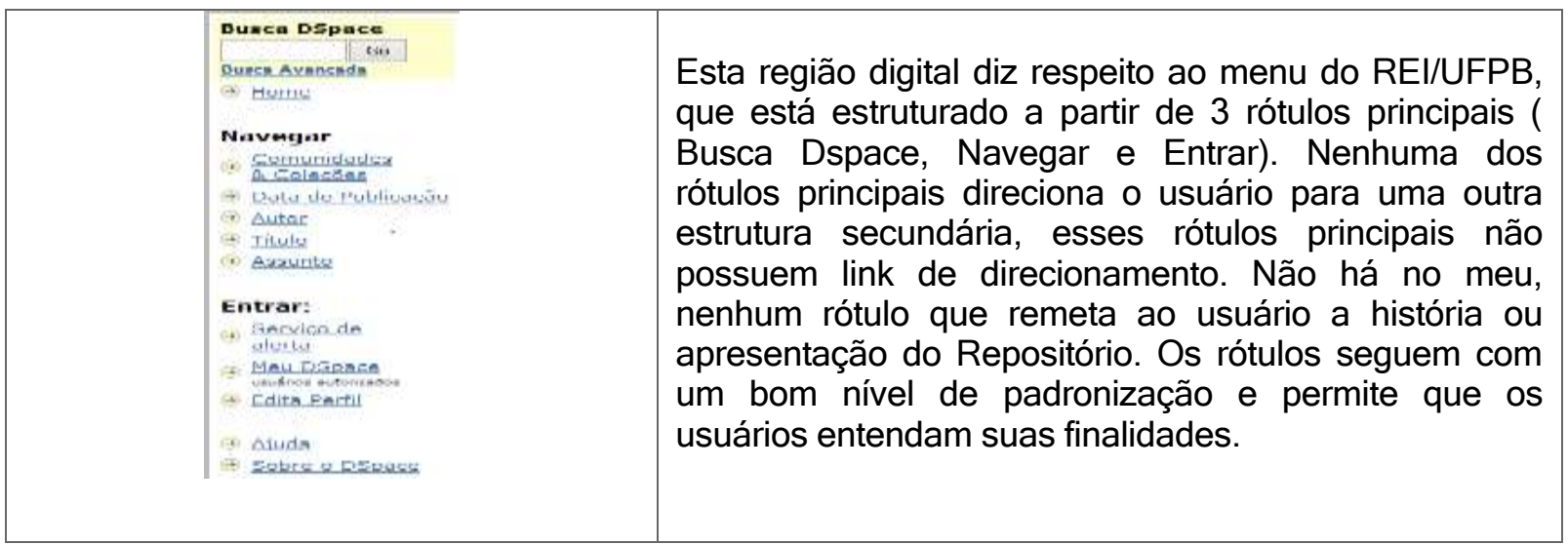

Fonte: Dados da pesquisa, 2016.

(Continuação)

\section{Quadro 1 - Análise do sistema de rótulos em regiões digitais do Repositório Eletrônico}

Institucional da UFPB

\begin{tabular}{|c|c|}
\hline 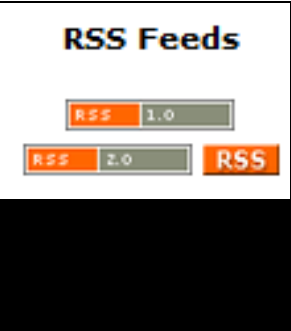 & $\begin{array}{l}\text { Este rótulo textual e imagético representam a } \\
\text { informação de que o usuário pode se inscrever para } \\
\text { receber as notícias do Repositório. Esse recurso é } \\
\text { bastante utilizado em sites/portais que mudam ou } \\
\text { atualizam o seu conteúdo regularmente. O que } \\
\text { observou-se é que as notícias do REl não são } \\
\text { atualizadas com frequência, tornando o recurso RSS } \\
\text { Feeds quase inutilizável. }\end{array}$ \\
\hline WBC ${ }_{1,0}^{\text {XHTML }}$ & $\begin{array}{l}\text { Este rótulo imagético remete ao usuário que o } \\
\text { Repositório segue padrões de acessibilidade da W3C } \\
\text { (World Wide Web Consortium). Caso o usuário clique } \\
\text { na imagem, é direcionado a página de validação do } \\
\text { padrão W3C, que mostra se o site/portal possui algum } \\
\text { erro relacionado a esses padrões que a W3C } \\
\text { estabelece. O que observou-se é que embora o REI } \\
\text { apresente esse rótulo em sua interface, o Repositório } \\
\text { possui } 8 \text { erros relacionados aos padrões W3C. }\end{array}$ \\
\hline DSpace Software & $\begin{array}{l}\text { O rótulo textual ao lado, está localizado no rodapé da } \\
\text { página do REI e é um rótulo que redireciona o usuário } \\
\text { ao que deveria ser o site do Dspace } \\
\text { (software/plataforma de criação do REI), contudo, ao } \\
\text { clicar na imagem, o link ao qual o usuário é } \\
\text { redirecionado não existe. }\end{array}$ \\
\hline Feedback & $\begin{array}{l}\text { Rótulo textual localizado no rodapé da página do } \\
\text { Repositório, direciona o usuário a uma subpágina } \\
\text { onde o usuário pode entrar em contato com a } \\
\text { Administração do REI. }\end{array}$ \\
\hline
\end{tabular}




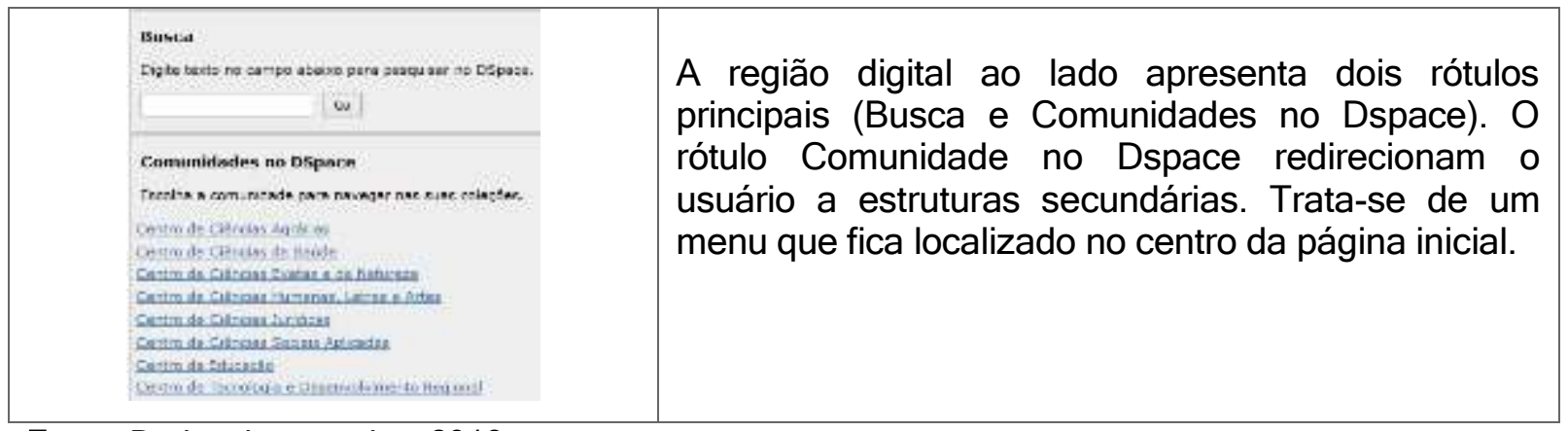

Fonte: Dados da pesquisa, 2016.

Pode-se observar que o Repositório Eletrônico Institucional da UFPB possui muitos rótulos textuais, ocupando muito espaço da página inicial do Repositório. Todavia, o REI não possui uma grande quantidade de informações, dessa forma os elementos apresentam-se de uma forma equilibrada.

\subsection{SISTEMA DE NAVEGAÇÃO}

Quando falamos em navegar, nos remete logo a ideia de explorar, executar um caminho, chegar a determinado lugar. Para tanto muitas vezes é necessário que planejemos a rota/o caminho por onde iremos passar para conseguir chegar a esse determinado lugar, a navegação em ambientes digitais não é tão diferente assim, muitas vezes precisamos conhecer, explorar, "passear" pelo site/portal para encontrar o que se está a procura, muitas vezes utilizando de recursos como um guia ou um mapa.

Dessa forma, podemos entender que o sistema de navegação na web está diretamente ligado ao pensamento de auxiliar o usuário em satisfazer as suas necessidades informacionais, tornando-se dessa forma um sistema fundamental para que o usuário não se perca pelos links/menus disponíveis no site/portal.

Rosenfeld, Morville e Arango (2015) explicam que os sistemas de navegação são compostos de vários elementos básicos ou subsistemas e podem ser dos seguintes tipos: sistemas globais, locais e contextuais de navegação que estão integrados nas páginas da web.

Reis (2007) explica que no que diz respeito aos elementos do sistema de navegação, pode-se classificar em dois subsistemas, a saber: o sistema embutido e o suplementar. Onde o sistema embutido seria composto por elementos apresentados junto com o conteúdo da página com a função de contextualizar o usuário e o sistema 
suplementar são elementos externos a hierarquia do site/portal, elementos que tem o intuito de provê caminhos suplementares para encontrar o que deseja e completar as tarefas, seriam os mapas de sites, índices, guias que existem fora as páginas de suporte.

Diante do exposto, o quadro 2 mostra a identificação e análise destes elementos do sistema de navegação no Repositório Eletrônico Institucional (REI) da UFPB.

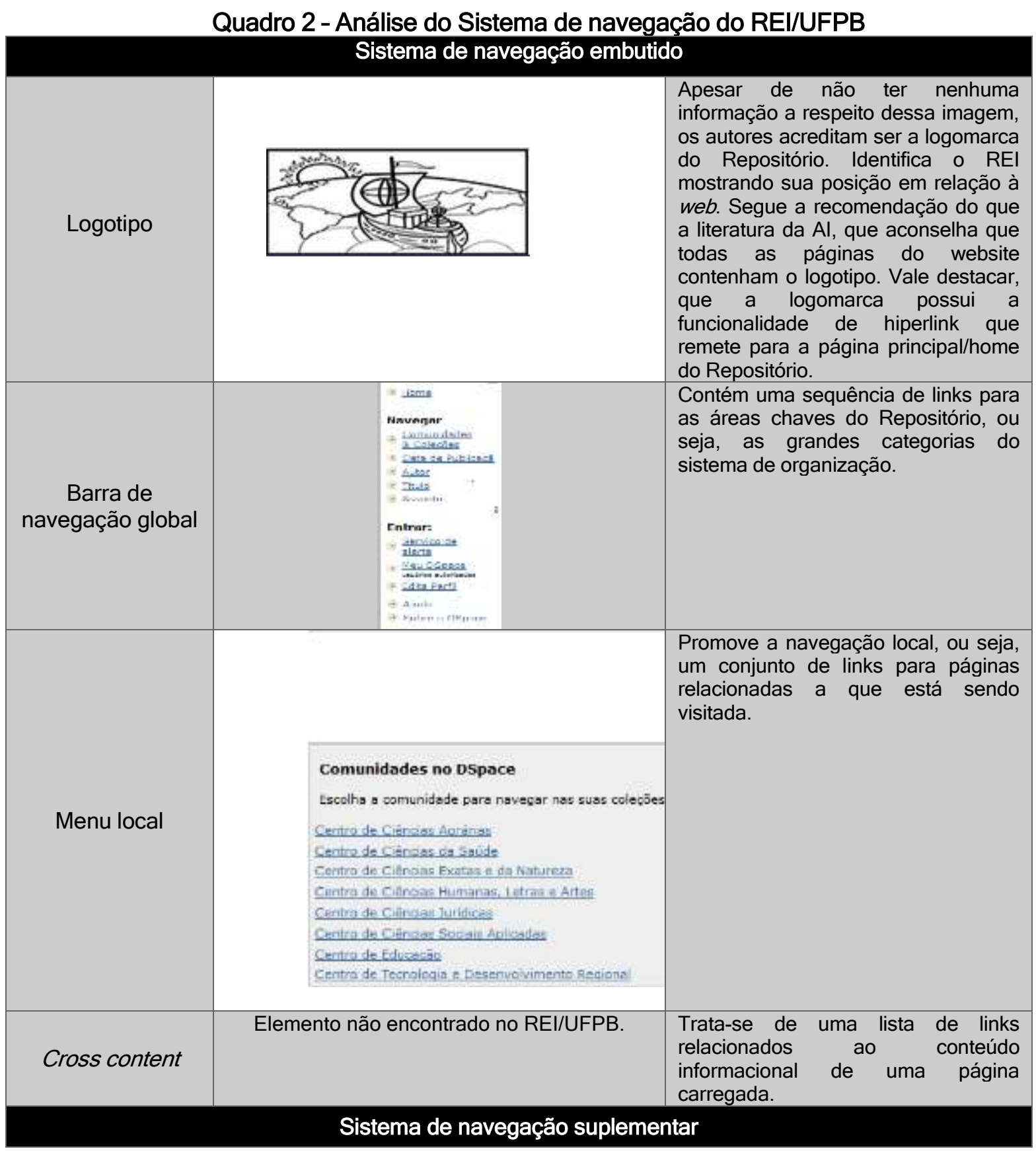




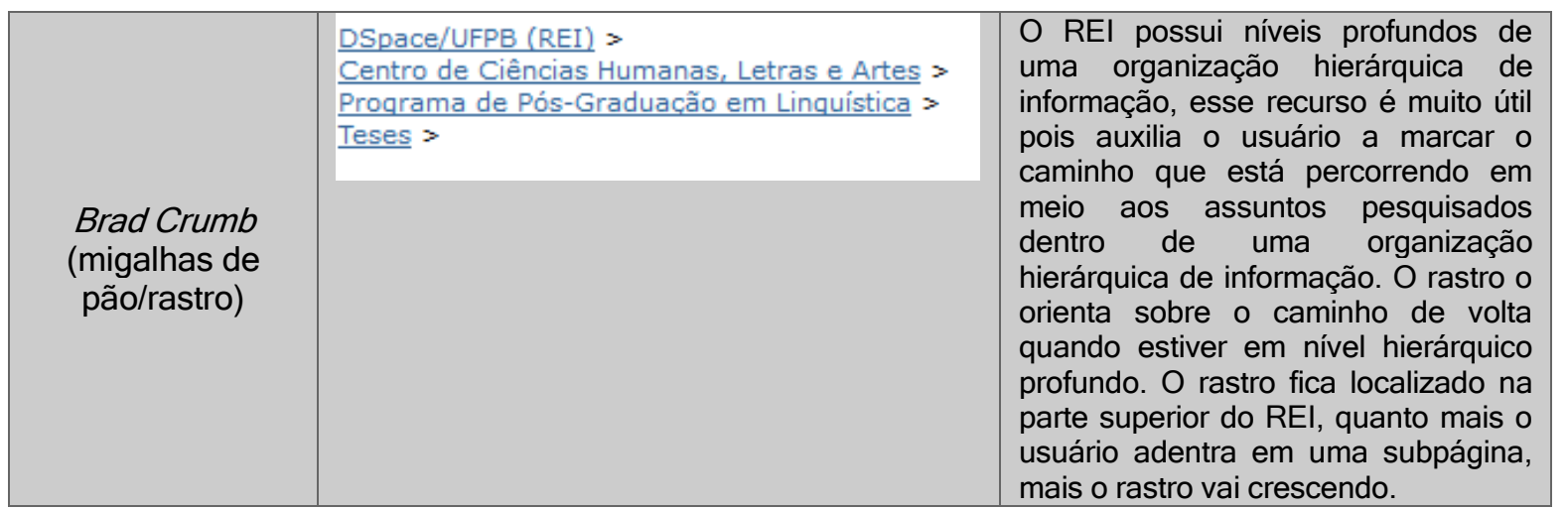

Fonte: Dados da pesquisa, 2016.

(Continuação)

\section{Quadro 2 - Análise do Sistema de navegação do REI/UFPB}

\begin{tabular}{|c|c|c|}
\hline Mapa do site & Elemento não encontrado no REI/UFPB. & $\begin{array}{l}\text { Tem função de apresentar a estrutura } \\
\text { analítica do website possibilitando o } \\
\text { acesso direto a uma página } \\
\text { específica. }\end{array}$ \\
\hline \multirow[b]{3}{*}{ Índice remissivo } & 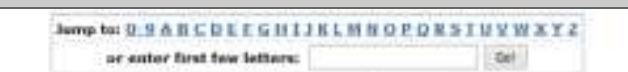 & \multirow{3}{*}{$\begin{array}{l}\text { Desobriga o usuário a passar pela } \\
\text { hierarquia primária do site e permite } \\
\text { acesso direto ao conteúdo. O REI } \\
\text { contém um indice remissivo de } \\
\text { assuntos organizado por ordem } \\
\text { alfabética. Vale ressaltar que o } \\
\text { usuário pode fazer a navegação pela } \\
\text { lista de autores também organizada } \\
\text { por ordem alfabética e pela ordem } \\
\text { cronológica, auxiliando e ampliando } \\
\text { as estratégias para recuperar a } \\
\text { informação desejada, o que para a } \\
\text { função do Repositório é de } \\
\text { fundamental importância. }\end{array}$} \\
\hline & 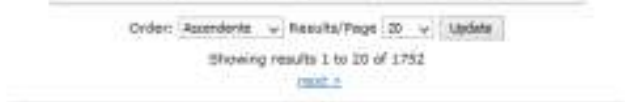 & \\
\hline & 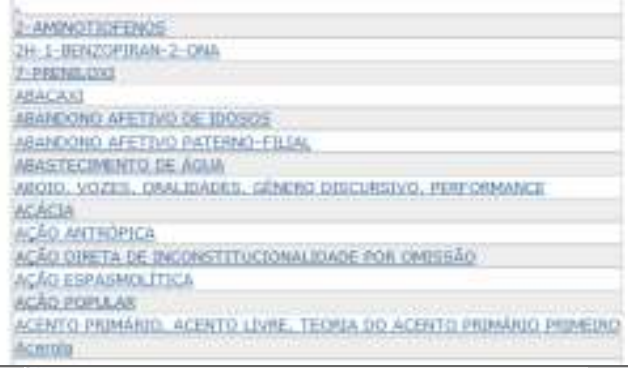 & \\
\hline \multirow[t]{2}{*}{ Busca e pesquisa } & $\begin{array}{l}\text { Busca } \\
\text { Digite terto no campo absixo para pesquisar no DSpace. }\end{array}$ & \multirow{2}{*}{$\begin{array}{l}\text { Foram identificados duas caixas de } \\
\text { busca/pesquisa. Tem o intuito de } \\
\text { auxiliar o usuário que já sabe o que } \\
\text { está procurando no Repositório. }\end{array}$} \\
\hline & 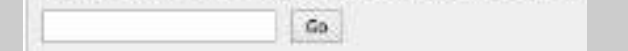 & \\
\hline
\end{tabular}

Fonte: Dados da pesquisa, 2016.

\subsection{SISTEMA DE BUSCA}

O sistema de busca é responsável pela localização de forma precisa do que se está procurando. A estratégia de busca quando bem implementada, auxilia os usuários a localizar um determinado conteúdo de seu interesse sem grande esforço.

Rosenfeld, Morville e Arango (2015) argumentam que o sistema de busca está relacionado ao sistema de rotulagem, ou seja, entende-se que está relacionada aos rótulos dos menus, itens desses menus, como ainda as opções disponibilizadas pelo sistema de navegação, pelos links e metadados utilizados para a indexação das páginas. 
Em relação ao Repositório Eletrônico Institucional da UFPB, executamos testes com as seguintes construções sintáticas: Educação, Direitos Humanos, Educação + Direitos Humanos e os resultados podem ser observados no Quadro 3.

Quadro 3 - Resultados de busca no REI/UFPB

\begin{tabular}{|c|c|}
\hline Construção semântica & Resultados com os hiperlinks \\
\hline Educação & $\begin{array}{l}\text { } 92 \text { itens } \\
1 \text { página/Comunidade dentro do REI (Centro } \\
\text { de Educação) } \\
\text { |91 hiperlinks para trabalhos que contenham } \\
\text { o metadado "Educação". }\end{array}$ \\
\hline Direitos Humanos & $\begin{array}{l}65 \text { itens } \\
1 \text { Coleção do REI (Direito) } \\
164 \text { hiperlinks para trabalhos que contenham } \\
\text { o metadado "Direitos humanos). }\end{array}$ \\
\hline Educação + Direitos Humanos & $\begin{array}{l}26 \text { itens } \\
1 \text { Coleção do REI (Direito) } \\
\mid 25 \text { hiperlinks para trabalhos que contenham } \\
\text { os metadados "Educação }+ \text { Direitos } \\
\text { humanos). }\end{array}$ \\
\hline
\end{tabular}

Fonte: Dados da pesquisa, 2016.

O sistema de busca do REI mostrou-se eficiente na localização e recuperação de resultados/itens, mostrando que quanto mais especificidade no que se procura menor pode ser a recuperação da informação desejada.

Contudo com relação aos resultados da terceira busca, observou-se que há bastante inconsistência entre a organização da informação e as expressões de resultado e as palavras-chave fornecidas, onde verificou-se que na primeira busca, dos 26 itens localizados, apenas 2 (duas) contém explicitamente as construções sintáticas de busca.

\section{CONSIDERAÇÕES FINAIS}

Frente a tudo o que fora exposto, faz-se necessário tecer as seguintes considerações.

A respeito da análise do Repositório Eletrônico da UFPB, verificou-se que há inconsistências/erros em vários sistemas, porém, o sistema que apresenta mais inconsistências/erros é o Sistema de organização, principalmente pela falta de informações que respondam as questões que costumeiramente são feitas pelos usuários.

Faz-se necessário uma atualização do próprio software/plataforma que o REI 
foi criado (Dspace) para que sejam utilizadas ferramentas e recursos mais atuais e dinâmicos pelos próprios administradores e para que possam oferecer aos seus usuários mais recursos de busca, acesso e interatividade.

Sugere-se uma customização/reformulação personalizada, com logotipo da Instituição mantenedora do Repositório, bem como informações a respeito de sua história de criação e outras informações que sejam pertinentes, sempre levando-se em consideração os pressupostos da Arquitetura da informação digital.

É de extrema relevância que o REl seja submetido a outras avaliações, levando-se em considerações outros aspectos que também são de fundamental importância, como por exemplo, os aspectos de usabilidade, acessibilidade como ainda um estudo de avaliação taxonômica dos metadados utilizados para a indexação de suas páginas/itens.

Por fim, ressaltamos que se aplicado os princípios orientados pela Arquitetura da informação digital nos sites/portais/repositórios durante a construção/ desenvolvimento destes, muitos problemas/complicações futuras podem ser evitadas.

\section{REFERÊNCIAS}

CAMARGO, Liriane Soares de Araújo; VIDOTTI, Silvana Aparecida Borsetti Gregório. Arquitetura da informação: uma abordagem prática para o tratamento de conteúdo e interface em ambientes informacionais digitais. Rio de Janeiro: LTC, 2011.

CONKLIN, Jeff. Hypertext: an introduction and survey. Computer, v. 20, n.9, p. 17-41, set. 1987.

ILHARCO, Fernando. Filosofia da Informação: uma introdução à informação como fundação da ação, da comunicação e da decisão. Lisboa: Universidade Católica Editora, 2003.

LIMA, Marcia H. T. de Figueredo. Consequências do movimento pelo livre acesso open access - e o direito à informação científica. In: SAYÃO, Luis. et al. Implantação

e gestão de repositórios institucionais: políticas, memória, livre acesso e preservação. Salvador: EDUFBA, 2009. 
LYNCH, Clifford A. Institutional repositories: essential infrastructure for scholarship in the digital age. ARL Bimonthly Report, 26, 2003. Disponível em: <http://www.arl.org/ newsltr/226/ir.html> Acesso em: 16 de jul. 2016.

MACEDO, Flávia Lacerda Oliveira de. Arquitetura da informação: aspectos epistemológicos, científicos e práticos. 2005. 190f. Dissertação (Mestrado em Ciência da Informação) - Faculdade de Ciência da Informação, Universidade de Brasília, Brasília, 2005.

MORESI, Eduardo (Org.). Metodologia da pesquisa. Brasília: Universidade Católica de Brasília, 2003. Disponível em: <http://http://www.unisc.br/portal/upload /com_arquivo/metodologia_da_pesquisa.pdf>. Acesso em: 9 out. 2013.

OLIVEIRA, Henry Poncio Cruz de. Arquitetura da Informação Pervasiva: contribuições conceituais. 2013. 203f. Tese (Doutorado em Ciência da Informação) - Faculdade de Filosofia e Ciências, Universidade Estadual Paulista, Marília, 2014.

OLIVEIRA, Henry Poncio Cruz de; VIDOTTI, Silvana Aparecida Borsetti Gregório. Arquitetura da informação digital: conexões interdisciplinares dentro da abordagem sistêmica. In: CAVALCANTE, Lídia Eugênia; BENTES PINTO, Virgínia; VIDOTTI, Silvana Aparecida Borsetti Gregório. Ciência da informação e contemporaneidade: tessituras e olhares. Fortaleza: Edições UFC, 2012. p. 184-202.

OLIVEIRA, Henry Poncio Cruz de; VIDOTTI, Silvana Ap. Borsetti Gregorio; BENTES, Virgínia. Arquitetura da informação pervasiva [recurso eletrônico] São Paulo: Cultura Acadêmica, 2015.

REIS, Guilhermo Almeida dos. Centrando a Arquitetura de Informação no usuário. 2007. 250f. Dissertação (Mestrado em Ciência e Artes) - Universidade de São Paulo, São Paulo, 2007.

ROSENFELD, Louis; MORVILLE, Peter; ARANGO, Jorge. Information Architecture for the Web and beyond. 4. ed. Sebastopol, CA: O'Reilly, 2015.

SAYÃO, Luis Fernando. MARCONDES, Carlos Henrique. Software livres para repositórios institucionais: alguns subsídios para a seleção. In: SAYÃO, Luis. et al. Implantação e gestão de repositórios institucionais: políticas, memória, livre acesso e preservação. Salvador: EDUFBA, 2009.

VIANA, Cassandra Lúcia de Maya; MÁRDERO ARELLANO, Miguel Ángel. Repositórios institucionais baseados em dspace e eprints e sua viabilidade nas instituições acadêmico-científicas. In: SEMINARIO NACIONAL DE BIBLIOTECAS UNIVERSITARIAS, 14. Anais....,2006. [Conference paper].

VIDOTTI, Silvana Aparecida Borsetti Gregório; CUSIN, César Augusto; CORRADI, Jiliane Adne Mesa. Acessibilidade digital sob o prisma da Arquitetura da Informação. In: GUIMARÃES, J. A. C.; FUJITA, M. S. L. Ensino e pesquisa em Biblioteconomia no Brasil: a emergência de um novo olhar. São Paulo: Cultura Acadêmica, 2008.

VON BERTALANFFY, Ludwig. Teoria geral dos sistemas. São Paulo: Vozes, 1975. 
